Max-Planck-Institut für demografische Forschung

Max Planck Institute for Demographic Research

Konrad-Zuse-Strasse 1 - D-18057 Rostock - GERMANY

Tel +49 (0) 3812081 - 0; Fax +49 (0) 3812081 - 202;

http://www.demogr.mpg.de

MPIDR WORKING PAPER WP 2013-014

OCTOBER 2013

\title{
Care for Money? \\ Mortality improvements, increasing intergenerational transfers, and time devoted to the elderly
}

\author{
Tobias C. Vogt (vogt@demogr.mpg.de) \\ Fanny A. Kluge (kluge@demogr.mpg.de)
}

This working paper has been approved for release by: James W. Vaupel (jwv@demogr.mpg.de),

Head of the Laboratory of Survival and Longevity and Head of the Laboratory of Evolutionary Biodemography.

(C) Copyright is held by the authors.

Working papers of the Max Planck Institute for Demographic Research receive only limited review. Views or opinions expressed in working papers are attributable to the authors and do not necessarily reflect those of the Institute. 


\title{
Care for Money? \\ Mortality improvements, increasing intergenerational transfers, and time devoted to the elderly.
}

\author{
Tobias C. Vogt and Fanny A. Kluge \\ Max-Planck-Institute for Demographic Research, Rostock, Germany
}

October 22, 2013

\begin{abstract}
Background: After the reunification of Germany, mortality among older eastern Germans converged quickly with western German levels. Simultaneously, the pension benefits of eastern Germans rose tenfold.

Objective: We make use of German reunification as a natural experiment to show that, first, increasing financial transfers from the elderly to their children led to increasing reverse transfers in the form of care; and, second, this rise in the number of hours spent on care led to a reduction in old-age mortality.

Method: As a first step, we calculated intergenerational transfer profiles by age for eastern and western Germany to determine whether any changes in downward and in upward transfers in the form of time and money occurred since reunification. We use generalized linear regression to test whether rising pensions led to an increase in the number of hours spent on care, and whether this increase led to a reduction in old-age mortality. We use different macro level data sources to test our hypothesis, including mortality rates and time use surveys for East and West Germany and information on private intergenerational transfers from the National Transfer Accounts project for Germany.

Results: We show that since German reunification, intergenerational downward transfers more than doubled in percentage terms in the east. This was predominantly caused by the sharp increase in pension benefits since the fall of the Berlin Wall. At the same time, mortality among pensioners dropped markedly, and converged
\end{abstract}


to western German levels. We further show that the rise in pension income was strongly correlated with the increase in social support and the decline in mortality among older eastern Germans.

Discussion: Our result suggest that there was an interfamilial monetary transfer from the elderly to the young in exchange for social support. This mutual beneficial exchange may have helped to improve the survival of older East Germans after the reunification. 


\section{Background}

There is an ongoing debate about the causal relationship between income and mortality (Smith, 1999). Despite increasing evidence that wealthier individuals tend to live longer, the causal direction and the underlying mechanisms are still being discussed (Cutler et al., 2006). Several studies have suggested that being in better health improves the ability of individuals to accumulate more human capital and income, which in turn lowers their mortality (Costa, 1994). The basis for future health and earnings may therefore be laid during the first years of a person's life (Bengtsson and Broström, 2009; Bengtsson and Mineau, 2009; van den Berg et al., 2006). External conditions, as well as the physical make-up of an individual, shapes his or her future health, and, consequently, his or her future wealth. Thus, the scarring hypothesis emphasizes that the strong association between income and mortality is largely attributable to cohort effects (Case et al., 2002). This implies that changes in the political, economic, or social environment which could influence income levels have a smaller impact on later life mortality once an individual is on the wrong track.

Despite the importance of early life conditions for later health and the ability to accumulate wealth, period effects even at higher ages still play an important role in shaping old-age mortality (Vaupel et al., 2003). Thus, changing income levels are important determinants of health and mortality, and are not merely outcomes of health. This association can be found within and between countries (Preston, 1975; Deaton, 2003). Increasingly, studies have shown that widening income inequality is related to disparities in mortality levels (Kitagawa and Hauser, 1973; Marmot, 2002). These findings appear to imply that the narrowing of income gaps may lead to a convergence of mortality levels.

For both directions of this association-i.e., from income to health and from health to income-a central question remains: Is there a direct relationship between survival and the amenities that money can buy, or is income associated with health through another, more complicated mechanism? Many studies have emphasized that income is a proxy for socioeconomic status and is an outcome of education or occupational status, which in turn determine mortality risks (Elo and Preston, 1996; Muller, 2002). However, these components of socioeconomic status cannot fully account for mortality differentials according to income groups. The effect of income still persists, even when education is taken into account (Blakely and Kawachi, 2002; Babones, 2008). Thus, income may 
influence health and mortality directly via the amenities it can buy. Wealthier individuals are able to afford commodities that promote health and survival, like better nutrition, improved housing conditions, or a general level of material security that makes it easier to cope with stressful events (Kuh and Ben-Shlomo, 2004; Barker, 1997; Wilkinson, 1997).

\subsection{Intergenerational transfers and mortality}

We seek to add to this discussion by testing another pathway through which income may influence health and mortality. We assume that higher income fosters intergenerational downward transfers, which may in return lead to rising upward intergenerational transfers in the form of care or general contact. Sociality in general is a major contributor to survival in animals and humans (House et al., 1988). Carey and Judge (2001) pointed out that human longevity is favored by social relationships and intergenerational transfers of resources. Thus, close family ties or social networks have been identified as crucial factors for later life well-being, health, and survival (Olsen et al., 1991; Kobrin and Hendershot, 1977; Anson, 2010; Steptoe et al., 2013). An increasing number of ties or contacts within a network has been shown to be associated with a lower mortality risk among the elderly (Eng et al., 2002; Berkman, 1995). Holt-Lunstad et al. (2010) summarize in an extensive review that social isolation at older ages is a health risk comparable to smoking or excessive alcohol consumption. Hence, incentives that encourage more connections between family members may be beneficial in terms of reducing mortality; in this context, a potential stimulus is increasing financial intergenerational transfers.

A number of scholars have explored the underlying motives for transfers. While public transfers are usually non-voluntary, the opposite is true for private transfers. The many studies that have examined the question of why private transfers arise have, for example, attributed them to pure altruism, as formulated in Becker (1974); to accidental bequests (Yaari, 1965; Barro and Friedman, 1977; Davies, 1981); and to the exchange motive (Cox, 1987). The research on motives has often been ambiguous, as can be illustrated by the findings on savings decisions. People may, for example, save with a bequest motive in mind, as Kotlikoff (1988); Kotlikoff and Summers (1981) has pointed out. According to this study, intergenerational transfers are the major component of wealth accumulation in the US. In contrast, Modigliani (1988) concluded that precautionary saving and uncertainty about the length of life often result in bequests. The joy of 
giving may also be a reason for such transfers. A comprehensive overview of transfer motives can be found in Lüth (2001).

We examine another assumption connected to the savings motive, which highlights that bequests are used strategically to reward desired behavior (Bernheim et al., 1985). Thus, increasing pension benefits may be used to motivate children or relatives to provide informal care or support with daily activities. In addition, in eastern Germany, downward intergenerational transfers increase the well-being of the middle-aged (Kohli et al., 2000), and play a more prominent role due to the disrupted labor market histories of many people in the east. The intergenerational solidarity which is found across European countries (Albertini et al., 2007), and which includes not just monetary but time transfers, should therefore foster the survival of the elderly.

We further assume that children may themselves be motivated to save, which in turn motivates them to foster their parents' survival. Living longer increases the wealth of their parents, who did not accumulate assets over the decades of German separation, but are instead receiving a relatively high and steady stream of pension payments after reunification, which could ultimately increase the size of their bequests. These mechanisms would increase old-age survival via rising income. The higher the potential downward transfers, the greater the incentive to provide upward transfers in the form of (informal) care. We are aware that there are many interactions, and that it is difficult to establish direct causal pathways. This paper is a first step in the investigation of the relationship between social support and old-age survival in the natural experiment context of eastern Germany.

\subsection{The German reunification - A natural experiment}

The testing of causal relationships is greatly facilitated when we are able to do so in the context of a natural experiment (Campbell and Stanley, 1966). Thus, the reunification of Germany provides us with a unique opportunity to test our hypothesis. A single population was divided into two groups over four decades, and each group was exposed to a different set of social, political, and economic 'treatments'. The unforeseen fall of the Berlin Wall ended the separation of the two groups rather abruptly, and in under a year eastern Germans had adopted the western German system. Eastern German life expectancy changed in response to the transformation of the society (see Figure 1). 
Figure 1: Life expectancy convergence between East and West Germany

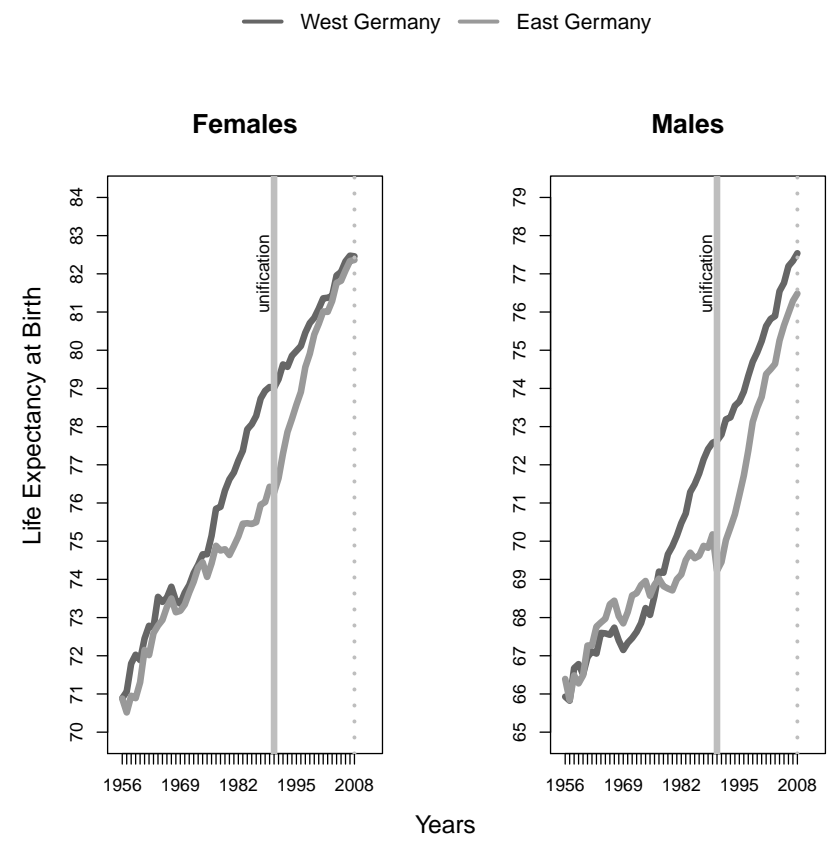

Source: Human Mortality Database (2012)

One of the main reasons for the convergence in mortality levels between eastern and western Germany was the increase in income after reunification (Diehl, 2008; Vogt and Kluge, 2012). The main beneficiaries of this increase were pensioners in the east, who indeed experienced the biggest gains in life expectancy, as can be seen in Figure 2. The age group 60 to 80 contributed almost half of all of the additional years of life expectancy. They benefited from the conversion of the East German to the West German mark, which increased their purchasing power up to tenfold, as well as from the adoption of the West German pension system (see Figure 3). ${ }^{1}$ A previous study showed that the period effect of increases in pension income was indeed associated with the catch-up in life expectancy for the elderly, and that pensioners with children benefited the most from rising retirement benefits (Vogt and Vaupel, 2010).

\footnotetext{
${ }^{1}$ The East German Mark was converted into the West German Mark with an exchange rate of 1:1. This parity greatly overrated the real value of the East German Mark. More realistic estimations range from between 5:1 and 10:1 (Neumann 1992, Baylis 1993).
} 
Figure 2: Differences in life expectancy for males and females between 1990 and 2008, contribution by age group

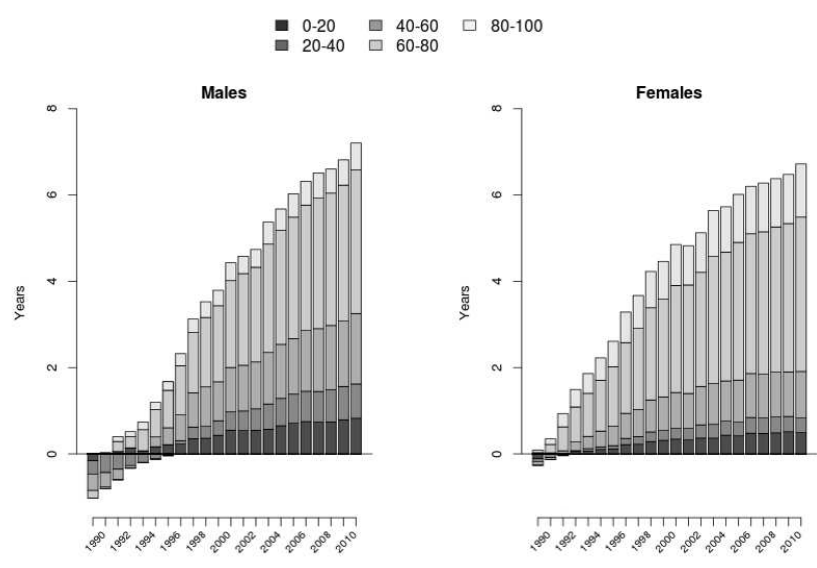

Source: Human Mortality Database (2012), Vogt (2013)

Figure 3: Convergence of monthly retirement benefits (both sexes)

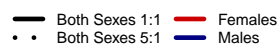

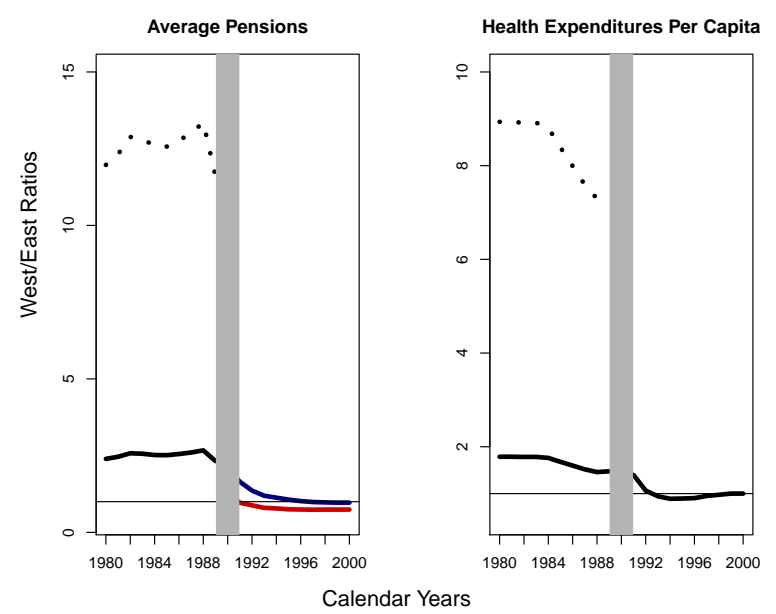

Source: Statistical Yearbooks of the FRG and GDR in the respective year

We make use of this setting to investigate the following questions: first, whether increases in retirement benefits lead to rising intergenerational transfers; second, whether 
increases in downward transfers entail rising upward transfers in terms of the time adult children spend with their elderly parents; and, third, whether this increase in upward transfers results in lower mortality among the elderly. While some studies have emphasized that networks were closer during the GDR era, we largely attribute this apparent closeness to supply shortages that increased the need for informal networks (Diewald, 1995). In contrast, Szydlik and Schupp (1998) argued that after reunification intergenerational relations became even stronger due to the greater degree of economic uncertainty. Meanwhile, Kohli et al. (2000) asserted that as the family ties have become stronger and the needs of the younger generations have become greater, private transfers from older generations to their descendants have occurred more frequently.

\section{Data and Methods}

The monetary estimates for private transfers are obtained by following the standard methodology of the National Transfer Accounts. The theoretical framework builds upon Samuelson (1958), Diamond (1965), and Lee (1994). Information on consumption, income, the age utilization of public expenditures and revenues, and corresponding private transfers is provided in the database for Germany. In order to construct the NTAs, a micro survey that estimates age utilization profiles is needed. The German Income and Expenditure Survey in 2003 (Einkommens- und Verbrauchsstichprobe, or EVS) serves as the micro foundation of the relative age shares. We chose the National Transfer Accounts for 1993 and 2003 because these years closely correspond to the time use estimates that are available for 1992 and 2002. The EVS is based on a representative quota sample of Germany's private households, and covers information on income, consumption, transfers, savings, and assets. The EVS for 2003 includes around 50,000 households, and is representative of households with a monthly net income of less than 18,000 euros. This limitation excludes only about two percent of all households. In addition to income and consumption, the EVS includes all of the relevant public transfers to households, and allows for estimations of private intra-familial flows. In addition to the intra-familial flows, we have information on inter-household transfers. We use the amounts given and received from other households in the respective year reported in the survey.

Population estimates are available in one-year age groups, and are provided by the German Federal Statistical Office for the computation of per capita values. We refrain from adjusting these inter-household transfers to a macroeconomic value simply because 
National Accounts do not offer this information. Thus, we believe the original reported values for transfers received hold true, and we adjust the transfers given accordingly.

Having outlined the methodology for obtaining the monetary lifecycle results, we add non-monetary transfers, such as informal care, to the picture. To estimate transfers in and between households, the Time Use Surveys 1991/92 and 2001/02 are employed. The scientific use files for Germany include 5,400 households, 12,600 individuals, and 37,700 diary entries for 2001/02. Individuals were asked to fill in a calendar for three representative days, reporting all of their activities that require at least 10 minutes of their attention. The time spent per day on cooking, cleaning, or caring for each individual of a respective age group is recorded. The survey in 1991/92 deviates from the later one in that it includes only around 7,000 households, 19,000 individuals and 32,000 diary entries, as individuals only kept a diary for two days. All individuals in the household above age 12 answered the questionnaire.

In addition, we use data from the German Socio-Economic Panel (GSOEP). This dataset includes very detailed information on objective and self-rated health measures and social interaction. It provides detailed statistics for selected years, such as the frequency of an individual's family contacts, any payments made to children, and, most importantly, the people the respondent can call upon for assistance. Unfortunately, these data are only available from 1995 onwards.

We first try to approach the question by showing some descriptive relationships between money and social interaction. We provide a schematic framework in order to assess the links in greater detail. We start by testing some of the relations in a logit model while making use of the advantageous panel structure of some of our data. First, we test whether increasing pension benefits in the east had an impact on the number of hours spent on intergenerational care. Here, we control for demographic factors like sex, age, and the number of children and grandchildren. Second, we seek to quantify the effect of the rising number of hours spent on care on mortality among the elderly. Here, we control for the same factors as we did in the first model. We run both models independently for eastern Germany and for western Germany as the control group. 


\section{Results}

The initial results showed a significant increase in monetary private downward transfers in the east. The strict downward flow of private transfers in the east for 1993 and 2003 was especially surprising, as previous studies have found that eastern German pensioners in the past have relied almost exclusively on public pensions, with assets playing only a minor role in their portfolios (Kohli et al., 2000; Kluge, 2010). Total private transfers, including intra- and interhousehold transfers, added up to 63 billion euros in the east (also including transfers to children under adult age). The percentage share of income transferred to the next generation by individuals aged 65 or older significantly increased in the east. While eastern German pensioners transferred 2.7 percent of their income to the younger generations in 1993, the share had increased to 5.7 percent in 2003. Even if the shares had stayed at the same level, the increase would have been substantial, as disposable income rose substantially. The finding that the share more than doubled within 10 years is remarkable, and it hints at an exchange or a solidarity motive.

Figure 4 shows the changes in income sources of the elderly in 1993 and 2003 at the population level. Focusing on the results for eastern Germany only, we can see that back in 1993, eastern pensioners relied almost exclusively on public transfers as their main source of income. The role of assets was negligible in financing their consumption, and they still transferred about $2.7 \%$ of their income to their descendants. A very different picture emerged 10 years later. By then, pensioners were financing $85 \%$ of their consumption with public transfers. In addition, they had accumulated some assets, and had more than doubled the percentage of their income they were transferring to their children and grandchildren. ${ }^{2}$ Private transfers over all age groups (measured within the National Transfer Accounts framework) increased substantially between 1993 and 2003. Whereas in 1993 individuals under age 50 reported receiving about two billion euros in transfers, this value increased tenfold in just a decade. The volume jumped from one percent of GDP to about seven percent of eastern German GDP. Some 40 percent of all inter-household transfers in the east were made by individuals older than age 65 ; this share clearly did not represent alimony payments between separated spouses. The immense increase in private transfers from the old to the young, which amounted to billions of euros, as well as the percentage of overall disposable income transferred,

\footnotetext{
${ }^{2}$ The data do not reveal to whom the money was given; we only know the age profiles of the senders and the recipients. Still, it is known that the majority of the transfers were given within bloodlines. This was especially the case for eastern Germany, where $75 \%$ of all transfers were made to younger family members, compared to $61 \%$ in the west (Kohli et al., 2000, p.93).
} 
Figure 4: Relative income sources of individuals age 65+, East and West Germany 1993 and 2003

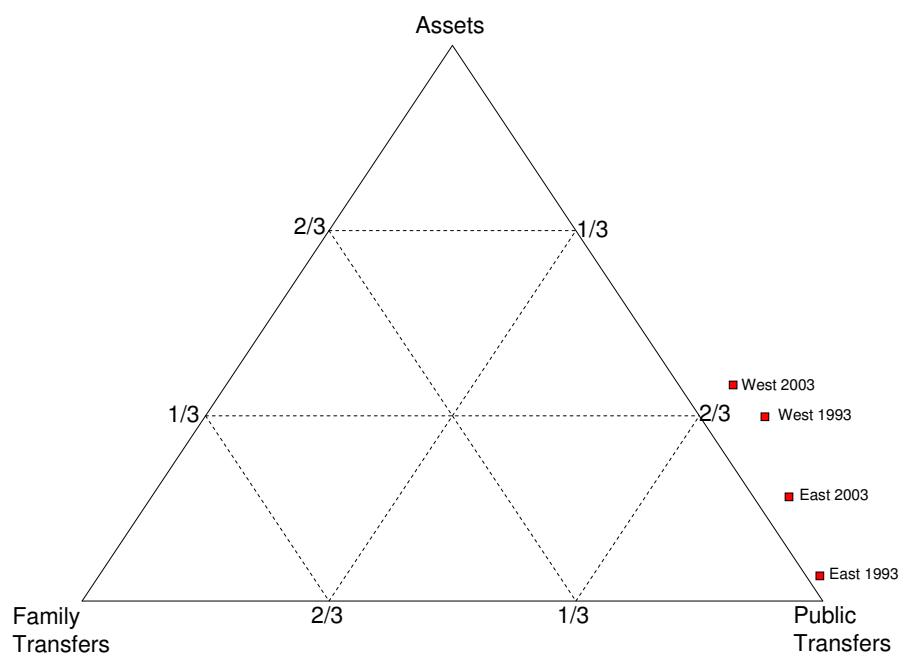

Source: Statistical Yearbooks of the FRG and GDR in the respective year, Income and Expenditure Survey 1993 and 2003 , own calculations, illustration adapted from Mason (2010)

demonstrates the willingness of the elderly to support their descendants, as Kohli et al. (2000) found.

The increase in monetary downward transfers toward younger family members is significant, and shows the importance of the adoption of the western German pension system for all eastern German citizens. It substantially increased family wealth overall, and that wealth was being shared across generations. The changes just described on the macro level were supported by micro-level data.

Figure 5 illustrates the per capita age profiles of inter-household transfers and how they changed within just 10 years (we show the original mean values by age and our smoothed estimates). These transfers were mainly reallocations from older individuals toward younger ones. In 1993, private inter-household transfers did not significantly differ from zero. We observed a small increase at ages 20 to 30 only. Due to the variable layout in the Income and Expenditure Survey, we could not fully distinguish alimony payments from one separated parent to the other. Still, given that the average age difference between partners in Germany is around three years (Klein, 1996), we 
Figure 5: Private inter-household transfers per capita, East Germany 1993 and 2003

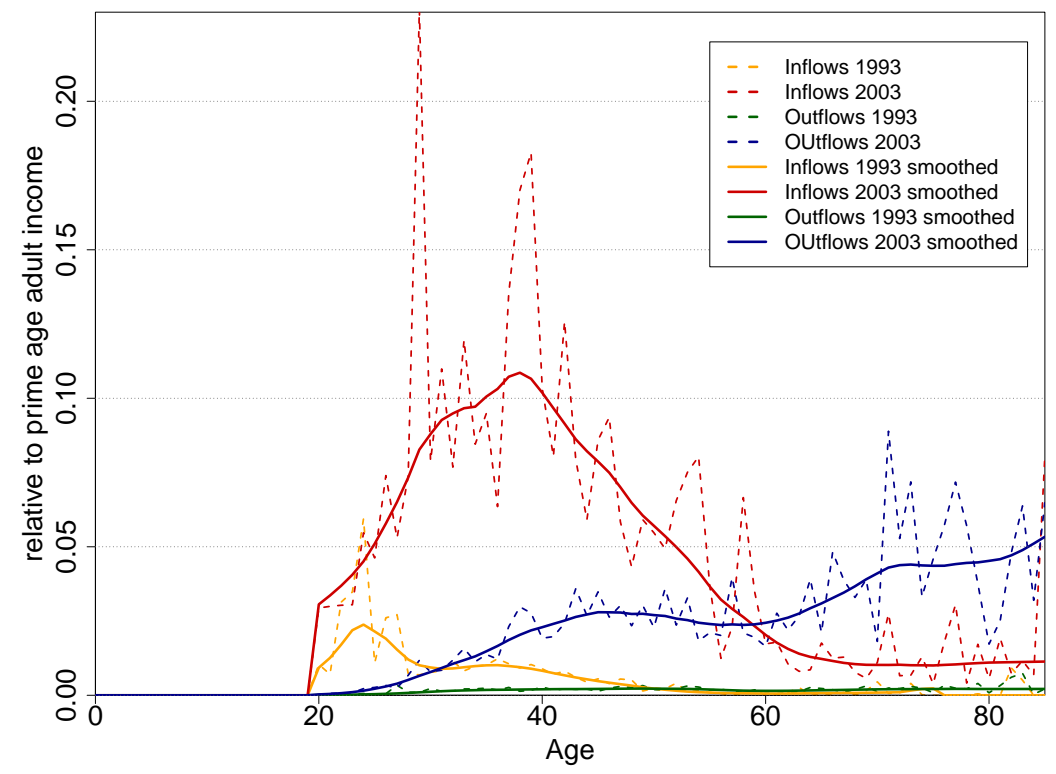

Source: Income and Expenditure Survey 1993 and 2003, National Transfer Accounts 1993 and 2003, own calculations

argue that payments of this kind would usually result in intra-age rather than inter-age reallocations. As we found that the givers and the recipients were usually not the same age, these were likely transfers between individuals of different generations. The changes in monetary transfer patterns were accompanied by changes in social support measures. To assess these changes in more detail, we employed the Time Use Survey for Germany and identified tasks that can be considered social support provided by family members to the elderly. These include housework and shopping assistance, but also general contact or simply time spent together. 
Table 1: Time Use Survey 1991/91 and 2001/2002

\begin{tabular}{lrrrr}
\hline & \multicolumn{2}{c}{$1991 / 92$} & \multicolumn{2}{c}{$2001 / 02$} \\
\hline & East & West & East & West \\
Total respondents Time Use Survey & 4437 & 15271 & 2497 & 11301 \\
Percentage share of people providing inter-household help & 7.6 & 9.6 & 11.5 & 10.1 \\
Average reporting inter-household help (in minutes) & $\mathbf{3 3}$ & $\mathbf{3 8}$ & $\mathbf{3 6}$ & $\mathbf{4 6}$ \\
Average reporting inter-household help aged 30-49 (in minutes) & 26 & 32 & 35 & 42 \\
Average reporting inter-household help aged 50-69 (in minutes) & 49 & 49 & 41 & 52 \\
Average reporting inter-household help aged 70-89 (in minutes) & 28 & 45 & 17 & 39 \\
\hline
\end{tabular}

Source: Time Use Survey 1991/92 and 2001/2002, own calculations

Table 1 displays some numbers on the share of respondents who provided inter-household help (excluding childcare), and the amount of time they devoted to these tasks. Interhousehold help includes performing any activity, such as going shopping, cleaning, or providing pet or eldercare, for a person not living in the same household. For the east, we found that in 1992 around $7.5 \%$ of the sample population reported providing interhousehold help, whereas in 2002 the share had increased to $11.5 \%$. While it is possible to argue that this was mainly due to decreases in female employment rates in the east, this explanation is unlikely, as these job losses had already occurred by 1992 (Grundig, 2008). A second possible explanation is that we have found a pure structural effect of age, and that the aging of the population led to an increasing number of elderly; however, this also seems unlikely as the share of individuals older than age 75 remained relatively stable over the period. Moreover the share of the oldest-old did not change considerably between 1993 and 2003 (3.5\%), although it did grow thereafter.

The amount of time devoted to providing care, cleaning, or shopping services to another household remained relatively stable, and added up to little more than half an hour each day. In the east, the main care givers were between ages 30 and 69. Compared to the west, relatively little help was provided by individuals above age 70 . The fact that an increase could be observed in the west is not a counter-argument. As western German pensioners were relatively wealthy and had accumulated assets, we expected to find that they had made substantial bequests. We also found that adult children and parents in the west were much more likely to live in the same house or very close by. This was not the case in the east, where homeownership rates were much lower. 
Figure 6: Time devoted to general social contacts and family contacts in minutes per day, East Germany 1993 and 2003

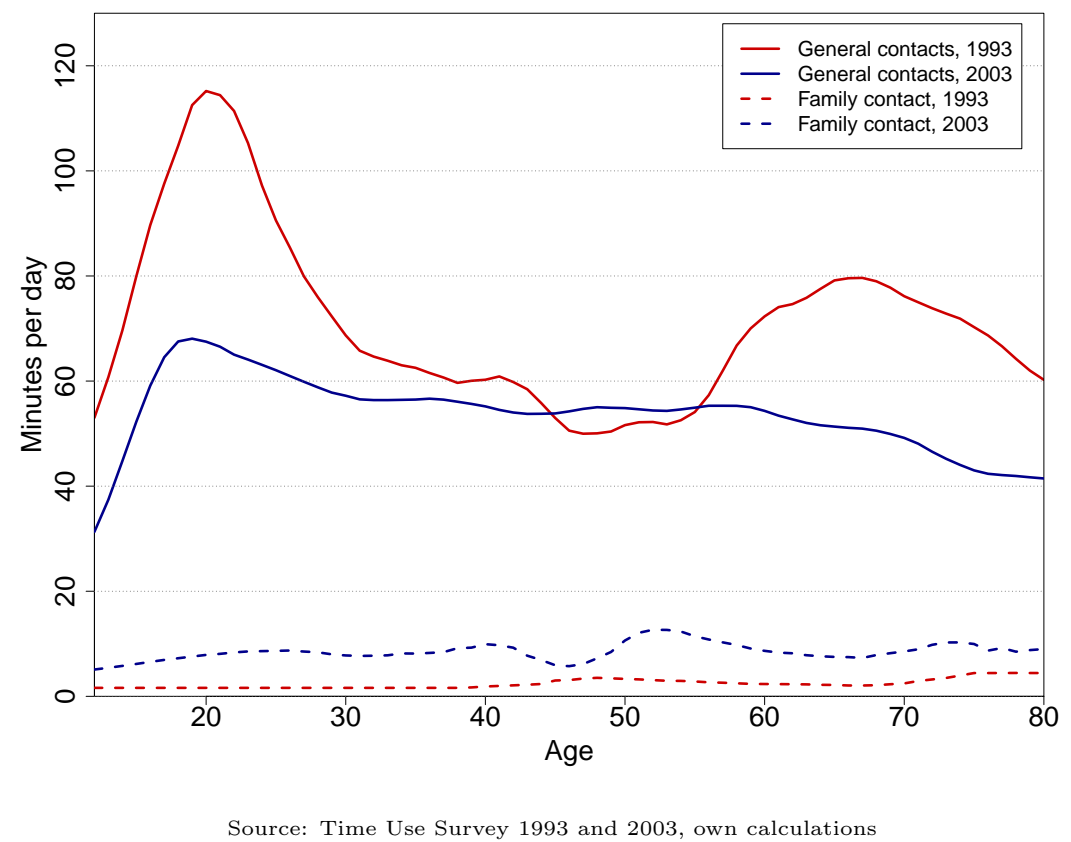

Moreover, the amount of time devoted to general contacts or social events, including personal talks, telephone calls, or activities with family members, increased in the east after reunification. Figure 6 shows how the frequency of social contacts in the east changed between 1992 and 2002. Although the number of hours spent with other people decreased and approached levels seen in the west, the amount of time spent with the family almost tripled. This would suggest that individuals reduced the amount of time spent with friends or acquaintances in times of economic uncertainty, and instead focused their social life on their family.

At the same time, mortality declined substantially, especially among individuals of retirement age. Their mortality rates quickly approached western levels. Our results suggest that old-age survival in East Germany was facilitated by increases in pensions, and the rise in intergenerational care provision and contacts that followed. Although we are aware that there were many changes during the period and that the pathways might be ambiguous, we would argue that these links observed at the macro level hint that there might be some correlation between mortality and various forms of social support. 
Figure 7: The relationship between social security, family ties, and life expectancy

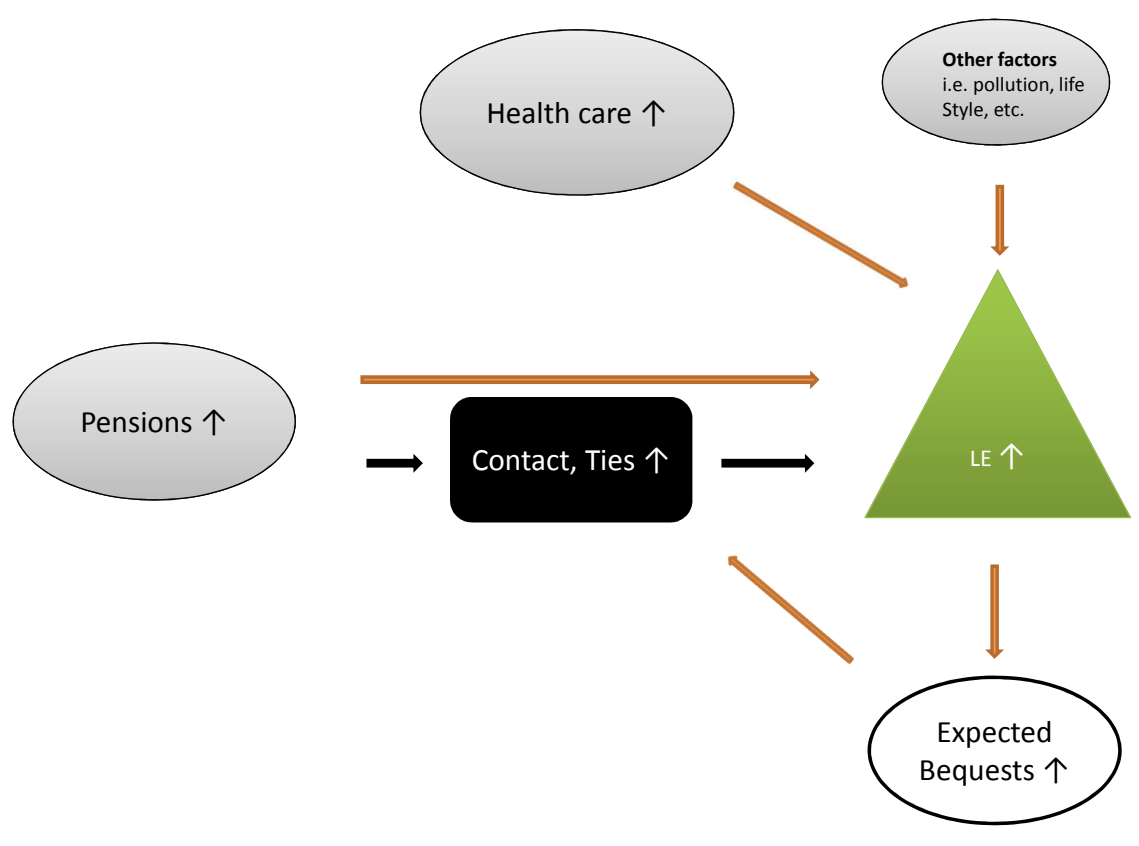

Source: own considerations

The framework we used to test our hypothesis in a model environment is shown in Figure 7. The impact of pensions, or, more generally, of income on life expectancy, has been well studied (as for example in Smith (1999); Cutler et al. (2006)). The assumption that health care has a direct impact on survival has also been well established (Farahani et al., 2010). However, less is known about the mediating effects of social contacts and ties, which may in turn be influenced by income and health. We assume that having a larger pension and being expected to make larger bequests would be associated with a higher frequency of family contact. This might have been the case here, as all forms of income among the elderly increased significantly. In addition, older individuals started to accumulate capital for the first time. Before reunification, eastern Germans saved relatively little, as their incomes were low and their public pensions were small. Second, luxury goods or other convenience goods were simply not available, and travel expenses 
were not relevant.

In a first step, we ran a logistic regression making use of the panel structure of the German Socio-Economic Panel (GSOEP). Here, we investigated how the impact of pension payments on the probability of an individual having frequent contact with his or her family differed between eastern and western Germany. We defined having a close relationship with other family members as engaging in daily to twice-weekly visits. The results are shown in Table 2. We found a significant impact of pension size on the number of family visits in the east.

Table 2: Determinants of frequency of family visits in East and West Germany in comparison, data GSOEP 1995 to 2005

\begin{tabular}{lrrr}
\hline & Coef. & Std. Err. & \\
\hline East & & & \\
age & -0.00652 & 0.010835 & \\
gender & 0.381086 & 0.222548 & $*$ \\
marital status & 0.157553 & 0.062073 & $* *$ \\
health status & -0.06611 & 0.100785 & \\
pension payment & 0.000447 & 0.000164 & $* * *$ \\
cons & -0.69902 & 0.908272 & \\
West & & & \\
age & -0.02073 & 0.007699 & $* * *$ \\
gender & 0.237215 & 0.16467 & \\
marital status & 0.124513 & 0.043977 & $* * *$ \\
health status & -0.04416 & 0.065757 & \\
pension payment & $-5.86 \mathrm{E}-06$ & $6.15 \mathrm{E}-05$ & \\
_cons & 1.054875 & 0.625299 & \\
\hline
\end{tabular}

\section{Discussion}

The aim of this study was to call attention to the following set of dynamics: namely, that the adoption of the western German pension system brought prosperity to the elderly in the east, which made them important actors in resource reallocation, and thus increased the desire of the young to care or spend time with their parents or grandparents, and that this increased interest in turn further fostered the survival of these pensioners. We are aware of the fact that with reunification, many key elements of people's lives changed at the same time, such as the labor market, health care provision, pension payments, environmental factors, and lifestyle factors. Nevertheless, it might 
be possible to identify some of the mechanisms behind these changes and their relative importance. We focused on old-age mortality, as these individuals did not have to worry about labor market interruptions, to identify differences in life expectancy according to family structure. The empirical results showed that there was indeed a significant increase in monetary downward transfers from old to young. The share of inter-vivo inter-household transfers more than doubled in the decade after reunification, and was accompanied by significant increases in public pension payments in the east. The newly acquired wealth of the elderly was shared across generations. At the same time, younger individuals, mainly in the age group 30-49, increased the amount of time they devoted to caring for their elderly family members. The descriptive estimates, together with the first model results, support our hypothesis regarding the beneficial relationship between social support, income, and survival.

In conclusion, we would argue that there is a link between increased pensions payments and old-age survival mediated by intergenerational transfers and social support. The relative importance of this link compared to that of other major factors, such as the direct effects of income, health care provision, pollution, or changing lifestyle factors, is as yet unknown. In order to further investigate this topic, we plan to use other data sources, such as the German Aging Surveys of 1996, 2002, and 2008, which offer rich data on support structures and on how these changed over time. We also have access to the Income and Expenditure Survey 1988 for the GDR, which will allow us to show the significant increase in family wealth through reunification. In addition, we would like to study whether similar family dynamics can be observed for western Germany during the period of the major pension expansion in the 1970s and 1980s, as well as after reunification. Moreover, western German pensioners are relatively wealthy compared to younger individuals, and thus should be seen as important actors with valuable resources. Unfortunately, a dataset that can account for all of the mortality-relevant factors that changed after reunification is not available. Despite these difficulties in estimating the relative importance of income for the mortality convergence between eastern and western Germany, we believe that this research can contribute to the discussion on the link between income and survival.

In the future, we would like to develop a structural equation model to show the relationships in greater detail, and could allow us to make some inferences about causality. We expect that the findings will provide insight into the nature of intergenerational ties and the motives for private transfers. This research has important implications for 
aging societies with a decreasing number of children and increasing bequest amounts per capita. Family ties might be strengthened in an aging society, as members of the younger generation anticipate inheriting larger amounts. 


\section{References}

Albertini, M., Kohli, M., and Vogel, C. (2007). Intergenerational transfers of time and money in european families: common patterns - different regimes? Journal of European Social Policy, 17(4):319-334.

Anson, J. (2010). Beyond material explanations: Family soliarity and mortality, a small area-level analysis. Population and Development Review, 36:27-45.

Babones, S. (2008). Income inequality and population health: Correlation and causality. Social Science and Medicine, 66:1614-1626.

Barker, D. J. P. (1997). Maternal nutrition, fetal nutrition, and disease in later life. Nutrition, 13:807-813.

Barro, R. and Friedman, J. (1977). On uncertain lifetimes. Journal of Political Economy, 85(4):843-849.

Becker, G. (1974). A theory of social interactions. The Journal of Political Economy, 82(6):1063-1093.

Bengtsson, T. and Broström, G. (2009). Do conditions in early life affect old-age mortality directly and indirectly? Evidence from 19th-century rural Sweden. Social Science and Medicine, 68:1583-1590.

Bengtsson, T. and Mineau, G. P. (2009). Early life effects on socio-economic performance and mortality in later life: A full life-course approach using contemporary and historical sources. Social Science and Medicine, 68:1561-1564.

Berkman, L. F. (1995). The role of social relations in health promotion. Psychosomatic Medicine, 57:245-254.

Bernheim, B. D., Shleifer, A., and Summers, L. H. (1985). The strategic bequest motive. Journal of Political Economcy, 93:1045-1076.

Blakely, T. A. and Kawachi, I. (2002). Education does not explain association between income inequality and health. British Medical Journal, 324:1336.

Campbell, D. T. and Stanley, J. C. (1966). Experimental and quasi-experimental design for research. 
Carey, J. R. and Judge, D. S. (2001). Life span extension in humans is self-reinforcing: A general theory of longevity. Population and Development Review, 27(3):411-436.

Case, A., Lubotsky, D., and Paxson, C. (2002). Economic status and health ind childhood: The origins of the gradient. American Economic Review, 95:1308-1334.

Costa, D. L. (1994). Health and labor force participation of older men, 1900-1991. NBER Working Paper, 4929:1-31.

Cox, D. (1987). Motives for private income transfers. The Journal of Political Economy, 95(3):508-546.

Cutler, D. M., Deaton, A. S., and Lleras-Muney, A. (2006). The determinants of mortality. NBER Working Papers, No. 11963:1-44.

Davies, J. (1981). Uncertain lifetime, consumption, and dissaving in retirementc. The Journal of Political Economy, 89(3):561-577.

Deaton, A. S. (2003). Health, inequality, and economic development. Journal of Economic Literature, 41:113-158.

Diamond, P. (1965). National Debt in a Neoclassical Growth Model. The American Economic Review, 55(5):1126-1150.

Diehl, K. (2008). Mögliche Ursachen für die rasche Reduktion der ostdeutschen Übersterblichkeit nach der Wiedervereinigung. Zeitschrift für Bevölkerungswissenschaft, 33:89-110.

Diewald, M. (1995). "Kollektiv", "Vitamin B" oder "Nische"? Persönliche Netzwerke in der DDR. Kollektiv und Eigensinn. Lebensverläufe in der DDR und danach. Berlin: Akademie Verlag, pages 223-260.

Elo, I. T. and Preston, S. H. (1996). Educational Differentials in Mortality: United States, 1979-85. Social Science and Medicine, 42:47-57.

Eng, P. M., Rimm, E. B., Fitzmaurice, G., and Kawachi, I. (2002). Social ties and change in social ties in relation to subsequent total and cause-specific mortality and coronary heart disease incidence in men. American Journal of Epidemiology, 155:700-709.

Farahani, M., Subramanian, S., and Canning, D. (2010). Effects of state-level public spending on health on the mortality probability in india. Health economics, 19(11):1361-1376. 
Grundig, B. (2008). Why is the share of women willing to work in East Germany larger than in West Germany? A logit model of extensive labour supply decision. Ifo Working Paper Series.

Holt-Lunstad, J., Smith, T. B., and Layton, J. B. (2010). Social relationships and mortality risk: A meta-analytic review. PLoS Med, 7(7):e1000316.

House, J., Landis, K., and Umberson, D. (1988). Social relationships and health. Science, 241(4865):540-545.

Human Mortality Database (2012). Human Mortality Database, volume March 11th. University of California, Berkeley (USA) and Max- Planck- Institut for Demographic Research, Rostock (Germany).

Kitagawa, E. M. and Hauser, P. M. (1973). Differential mortality in the United States: A study of socioeconomic epidemiology. Cambridge: Harvard University Press.

Klein, T. (1996). Der Altersunterschied zwischen Ehepartnern. En neues Analysemodell. Zeitschrift für Soziologie, 25(5):346-370.

Kluge, F. A. (2010). How East and West Germans finance their lifecycle consumption: evidence from NTA. MPIDR Working Paper, 027.

Kobrin, F. E. and Hendershot, G. E. (1977). Do Family Ties Reduce Mortality? Evidence from the United States, 1966-1968. Journal of Marriage and Family, 39:737-745.

Kohli, M., Künemund, H., Motel, A., and Szydlik, M. (2000). Families apart? Intergenerational Transfers in East and West Germany. In Arber, S. and Attias-Donfut, C., editors, The myth of generational conflict: The family and state in ageing societies, pages 88-99. London: Routledge.

Kotlikoff, L. and Summers, L. (1981). The role of intergenerational transfers in aggregate capital accumulation. The Journal of Political Economy, 89(4):706-732.

Kotlikoff, L. J. (1988). Intergenerational Transfers and Savings. The Journal of Economic Perspectives, 2(2):41-58.

Kuh, D. and Ben-Shlomo, Y. (2004). A life course approach to chronic disease epidemiology. Oxford University Press. 
Lee, R. (1994). The Formal Demography of Population Aging, Transfers, and the Economic Life Cycle. In Martin, L. G. and Preston, S. H., editors, Demography of Aging, pages 8-49. National Academy Press Washington, DC 1994.

Lüth, E. (2001). Private Intergenerational Transfers and Population Aging: The German Case. Physica Verlag.

Marmot, M. (2002). The influence of income on health: views of an epidemiologist. Health Affairs, 21:31-46.

Modigliani, F. (1988). The role of intergenerational transfers and life cycle saving in the accumulation of wealth. The Journal of Economic Perspectives, 2(2):15-40.

Muller, A. (2002). Education, Income Inequality and Mortality: a multiple Regression Analysis. British Medical Journal, 324:1-4.

Olsen, R., Olsen, J., Gunner-Svensson, F., and Waldstrom, B. (1991). Social networks and longevity. A 14 year follow-up study among elderly in Denmark. Social Science E Medicine, 33(10):1189-1195.

Preston, S. H. (1975). The changing relation between mortality and level of economic development. Population Studies, 29:231- 248.

Samuelson, P. A. (1958). An Exact Consumption-Loan Model of Interest with or without the Social Contrivance of Money. The Journal of Political Economy, 66(6):467-482.

Smith, J. P. (1999). Healthy bodies and thick wallets: The dual relationship between health and economic status. The Journal of Economic Perspectives, 13:145-166.

Steptoe, A., Shankar, A., Demakakos, P., and Wardle, J. (2013). Social isolation, loneliness, and all-cause mortality in older men and women. Proceedings of the National Academy of Sciences, 110(15):5797-5801.

Szydlik, M. and Schupp, J. (1998). Stabilität und Wandel von Generationenbeziehungen. Zeitschrift für Soziologie, 27(4):297-315.

van den Berg, G. J., Lindeboom, M., and Portrait, F. (2006). Economic conditions early in life and individual morality. The American Economic Review, 96:290-302.

Vaupel, J. W., Carey, J. R., and Christensen, K. (2003). It's never too late. Science, 301:1679-1681. 
Vogt, T. (2013). How many years of life did the Fall of the Berlin Wall add? A Projection of East German life expectancy. Gerontology, DOI: 10.1159/000346355 (published online: February 12, 2013).

Vogt, T. and Kluge, F. A. (2012). Can public spending reduce mortality disparities? Findings from East Germany after reunification. In Population Association of Amer$i c a$.

Vogt, T. C. and Vaupel, J. W. (2010). Do increases in income yield higher life expectancy? Findings from Eastern Germany after reunification. In Population Association of America. (in preparation).

Wilkinson, R. G. (1997). Socioeconomic determinants of health: Health inequalities: relative or absolute material standards. British Medical Journal, 314:591.

Yaari, M. (1965). Uncertain lifetime, life insurance, and the theory of the consumer. The Review of Economic Studies, 32(2):137-150. 